\title{
Contextos globais, textos locais: a relevância de Hall para uma analítica da globalização
}

\author{
Erik W. B. Borda*
}

Resumo: Neste trabalho propomos, através de um deslocamento nas discussões comuns sobre global/local, discutir e defender a não incompatibilidade entre textos produzidos localmente, referentes a situações empíricas limitadas, e seus contextos globais mais amplos. Para isso fizemos um balanço de parte da bibliografia que trata de discutir a "temática da globalização", identificando tendências e avaliando algumas de suas implicações e pressupostos para se teorizar o global de maneira crítica. Encontramos no tipo de trabalho produzido por Stuart Hall contribuições para o tema, as quais tentamos explicitar e trazer à tona. Ao final, propomos algumas saídas para as questões levantadas com base em articulações teóricas encontradas em diferentes campos do saber, seja na Sociologia, na Antropologia, nos Estudos Culturais, na Crítica Pós-colonial, e na mais recente perspectiva Decolonial.

Palavras-chave: Globalização, Stuart Hall, Sociologia, Decolonial, Antropologia.

\section{Entrada}

Quando estudamos determinados conjuntos de relações que comumente denominamos globalização, imediatamente uma ampla gama de problemas nos parecem interpelar. Em primeiro lugar, qual a natureza dos fenômenos que nos propomos a estudar? E, uma vez conscientes da natureza dos processos ou do tipo de relações por ele engendrados, como os interpretamos analiticamente? Com que metodologias? E 'last but no least', quais as possibilidades de uma prática política sob essas condições? Aihwa Ong e Stephen Collier (2005) apontam para três tendências no estudo do fenômeno. Primeiramente, abordagens que se voltam a grandes tratados sobre a nova ordem das coisas ou macroprocessos. 0 segundo tipo tenta examinar as articulações e resistências entre dinâmicas locais e contextos globais mais amplos. 0 último tipo, por sua vez, foca-se na reconstituição de categorias das Ciências Sociais de novas maneiras. É claro que, por fim, os autores propõem uma saída aos paradigmas apresentados, ao abordar a problemática de como arranjos distintivamente globais articulam as "grandes mudanças estruturais" como a "tecnociência, circuitos de trocas lícitas e ilícitas, sistemas de administração ou governo, regimes de ética ou valores" '(idem, p. 4). De qualquer maneira, em todos os casos há o consenso de que se lidam com um novo padrão de relações que são, evidentemente, globais.

Para fins analíticos, operaremos neste texto a partir de uma distinção que, se por um lado não totalmente se afasta da oferecida por Ong e Collier, por outro pode proporcionar um tipo de prática que nos permite uma saída diferente da oferecida

\footnotetext{
* Graduando em Ciências Sociais - UFSCar

${ }^{1}$ Agradeço às contribuições da professora Catarina Morawska Vianna sobre a versão inicial do manuscrito, sem as quais este trabalho poderia muito bem ter descarrilhado em direção a debates infrutíferos. Evidentemente, os pontos fracos devem ser apenas creditados ao autor deste texto.

1 Tradução livre.
} 
pelos autores. Diferente pois parte de uma concepção de teoria que é em si substancialmente deslocada, que visa menos dar inteligibilidade a fenômenos do que a transformação de uma dada realidade. Assim, longe de nos preocuparmos com os "problemas antropológicos" que emergem das formas globais articuladas em situações localmente específicas, voltar-nos-emos aos problemas éticos e políticos subjacentes. Nossa tarefa aqui é nada mais nada menos que tentar dar uma resposta "localizada" a uma questão: há uma incompatibilidade entre Teorias produzida conjunturalmente e cenários globais? No percurso de resposta à pergunta nos distanciaremos de duas formas de pensar global/local que, em nossa leitura, são insuficientes, e com isso nos colocaremos mais próximos de uma terceira opção. A primeira abordagem se refere àquelas que veem o global como um contexto. A segunda lida com o global como algo que está em todos os lugares. A última, por sua vez, foca-se em fluxos translocais a partir de um modelo explicativo específico, e é a saída que melhor nos serve neste trabalho. Essas tendências devem ser entendidas aqui como simplificações com fins puramente analíticos, como polarizações de um debate que é sempre necessariamente mais complexo. Isso porque cada um dos paradigmas se escreve em estreita relação com seus concorrentes, sempre apontando para o "elemento negligenciado" da abordagem oposta, o que faz com que as diferentes teorias oscilem entre tais tendências, aproximando-se em maior ou menor medida de cada um dos polos da tríade, mas sem necessariamente se enquadrar de maneira restrita a uma só macrotendência.

0 global como contexto é talvez a tendência mais comum nos estudos da globalização, e, grosso modo, diz respeito principalmente às abordagens encontradas em autores marxistas ou simpáticos a esse escopo teórico. Esta abordagem se destaca por ter como garantida a existência de forças globais, que são por sua vez autônomas e que podem/devem ser analisadas dessa forma. Os estudos, por exemplo, não raras vezes assumem o retrato do choque entre um capitalismo mundial e suas perversas lógicas expropriatórias com os interesses de grupos locais em alguma região do sudeste asiático ou no coração da floresta amazônica. Dentro desse paradigma, é facilmente discernível o que se entende como global - os interesses de grandes empresas e da burguesia internacional - e local - as práticas e dinâmicas culturais de populações nativas sujeitas a esse poder "que vem de cima". Tamanha é a cisão entre global e local dentro dessa tendência que a própria possibilidade de se fazer uma etnografia ou antropologia sob essas condições "pode não passar de um oximoro"2. (Burawoy, 2000. p. 1). Para os fins deste ensaio, a abordagem apresentada tem a grande vantagem de ancorar sua interpretação na materialidade do sistema-mun-

\footnotetext{
2 Tradução livre.
} 
do, o que significa facilitar o caminho de construção de uma prática política global. Embora não possamos negar que haja, de fato, um poder relativamente concentrado que subjuga determinados grupos a sua lógica, a visão bipartida e assimétrica entre local e global encontrada em tal abordagem muitas vezes não consegue dar conta da capilaridade dos laços que vinculam essas duas instâncias, e principalmente o porquê da aparente contraditoriedade das relações entre elas, que são muito mais ambivalentes e articuladas do que tais teorias querem nos fazer pensar.

Uma outra saída para dar conta dessa questão foi mais bem desenvolvida em parte da Antropologia que se voltou ao estudo da globalização. Diferentemente da abordagem anterior, esta foca-se em como formas globais interagem com outros elementos, engendrando um campo comum de inter-relações instáveis (ONG et CoLLIER, op. cit.). De fato, uma forma acabada do paradigma é apreciada justamente na obra de Ong e Collier que mencionamos acima que, ao focar-se nessas interações entre diferentes elementos, chama a atenção para a emergência de articulações temporárias, um arranjo (assemblage). "Em relação ao 'global', o arranjo não é uma 'localidade' a qual forças globais estão contrapostas. Nem é o efeito estrutural de tais forças. Um arranjo é o produto de múltiplas determinações que não são redutíveis a uma única lógica. (grifo meu)”3 (idem, p. 12) Na visão dos autores, esses arranjos se configuram em problemas antropológicos que devem ser etnografados. Talvez o mérito principal de tal abordagem se assente na visão multifacetada e estruturada das relações entre global e local, em que nenhum elemento tem primazia sobre o outro. Isso permite que se explicitem as contradições entre local e global, relativamente ausentes no primeiro paradigma. Não obstante, a autonomização de todas variáveis que formam um "assemblage" corre em grande medida o risco de não permitir a identificação de pontos eficientes ou "seguros" de adesão à luta política, que na primeira das tendências se assentaria muito provavelmente em seu materialismo. Qual a possibilidade de crítica aqui? Esse é um problema que os próprios autores enxergam, embora digam que sua abordagem "não sugere a ausência de uma instância crítica", apenas que as "avenidas de resposta não são sempre imediatamente óbvias." (id. ibid. p. 17). A combinação de tal paradigma com o anterior, ao invés de um mero contraste improdutivo, é uma das metas deste ensaio. Como pensamos de maneira problemática as relações entre cultura, poder, economia e sociedade sem nos deixarmos com isso cair em alguma espécie de impetuoso ceticismo pós-moderno?

Por fim, a última tendência, que se apresenta de maneira original no debate na medida em que vê a imprescindibilidade de conexões globais para o funcionamento do capitalismo, da ciência e da política (universais) e, ao mesmo tempo, veri-

\footnotetext{
${ }^{3}$ Tradução livre.
} 
fica que estes apenas podem ser decretados na materialidade de encontros práticos (Tsing, 2005). Ao invés de se pensar o global como diferente do local, e por conseguinte, as relações manifestas daquele neste, ou os dois como interpenetrados, de fronteiras borradas, o paradigma aqui em questão vai muito mais na direção de pensar o problema local/global como uma unidade diferenciada - no sentido marxista. Queremos dizer que nesta vertente global e local são dois lados da mesma moeda, sem que qualquer um tenha primazia sobre o outro e sem que haja uma confusão entre as duas instâncias. Anna Tsing em seu livro Friction: an ethnography of global connection tem uma das mais provocativas propostas no que concerne à Antropologia dentro desse paradigma, ao ter como escopo de sua análise as fricções entre diferentes dinâmicas. 0 central aqui é que a "fricção é requerida para manter o poder global em movimento", ao mesmo tempo em que ela não mero sinônimo de resistência, uma vez que a "hegemonia é feita assim como desfeita com a fricção." (Idem, p. 6). Em relação ao resto das Ciências Sociais, são os autores decoloniais que têm produzido perspectivas igualmente instigantes dentro dessa abordagem, como Mignolo, Coronil, Lander e outros. É digna de consideração a centralidade da agenda política para os diferentes autores que se enquadram nesta ampla tendência, como a própria Tsing, que tenta em seu texto responder a uma pergunta não tão distante da desenvolvida neste ensaio: "Por que o capitalismo global é tão bagunçado? Quem fala pela natureza? Que tipos de justiça social fazem sentido no século XXI?" (id. ibid. p. 11). Igualmente interessante também é notar que as saídas ou respostas para essas questões são muito similares entre os diferentes autores, e se assentam especialmente no papel dos "universais" para o movimento do "global". Voltaremos a esse tema na terceira parte. 0 que interessa reter aqui é que o horizonte analítico ou a escala - em termos de magnitude e domínio ${ }^{5}$ - desses autores funciona no "in -between" das abordagens anteriores ${ }^{6}$. Em suma, enquanto o primeiro paradigma peca ao negligenciar as complexas contradições ou complexidades contraditórias inerentes às relações global/local e tende a ser monocausal em forma, e o segundo, por outro lado, ainda que tenda a ser mais pluralista em sua ênfase, peque em não explicitar os vínculos entre os casos pesquisados e a materialidade das relações de poder globais que sustentam as possibilidades das conexões translocais, a última tendência opera a partir das lacunas das anteriores, configurando-se assim como o substrato de nossas análises no restante deste ensaio.

\footnotetext{
4 Tradução Livre.

5 Ver Strathern (2004).

${ }^{6}$ Isso não significa que essa tendência se apresente da mesma maneira na Antropologia, Tsing, e na perspectiva Decolonial, Mignolo. A primeira está muito mais interessada nas formas de se etnografar os universais, e a segunda, nas formas políticas de se operacionalizar a construção de uma hegemonia a nível global.
} 


\title{
1.1 Abstrações
}

Gostaríamos de voltar rapidamente para a dimensão conceitual do problema colocado pela globalização. Há uma antinomia hoje muito similar à destacada por Marx na introdução de $1857^{7}$, a saber, que certos conceitos tidos como pontos de partida são, na verdade, pontos de chegada. 0 mesmo acontece quando falamos em global e globalização para dar conta de uma gama de processos muito ampla, cujos efeitos, não raras vezes, levam-nos a certos binarismos maniqueístas - como "globalizar-se" X "defender a identidade" -, ou ainda, a um fato curioso apontado por Néstor García Canclini:

\begin{abstract}
Apesar desses resultados duvidosos, a uniformização do mundo num mercado planetário é consagrada como o único modo de pensar, e quem ousa insinuar que as coisas poderiam funcionar de outro modo é desqualificado como nostálgico do nacionalismo. E se alguém ainda mais ousado não apenas questionar os benefícios da globalização mas também a ideia e que a única forma de realiza-la é por meio da liberalização mercantil, esse será acusado de saudosista de tempos anteriores à queda de um insuportável muro. Como nenhuma pessoa sensata acredita que se possa voltar àqueles tempos, conclui-se que o capitalismo é o único modelo possível para a interação entre os homens e a globalização sua etapa superior e inevitável (CANCLINI, 2007. p. 8).
\end{abstract}

Acabaríamos nós, cientistas sociais, muitas vezes naturalizando aquilo mesmo que nos propomos a analisar e muitas vezes criticar? Acreditamos que dando como garantida a existência de padrões que conformam uma certa "globalização" imaginada - ignorando o caráter metafórico que assume tal conceito - não conseguimos perceber o grau de abstração em que se encontram as categorias com as quais trabalhamos. A dicotomia global/local e a hipervalorização de alguma das duas dimensões se torna, assim, não um problema e uma construção social, histórica e intelectual específica, mas o estado inevitável das coisas, tanto cultural quanto economicamente. Defenderemos aqui uma aproximação um pouco diferente ao problema, ao indagar precisamente o que está colocado quando metaforizamos e narramos a globalização a partir da lógica do neoliberalismo - muito menos uma teoria econômica do que um discurso hegemônico de um modelo civilizatório, uma síntese dos pressupostos e valores da sociedade liberal moderna (LANDER, 2011). Por isso é preciso considerar a feição necessariamente metafórica do(s) termo(s) globalização(ões), uma abstração, sem dúvida, mas sem a qual o pensamento se torna excessivamente obscuro. Na realidade, trabalharemos sempre - como se comprovará ao final deste texto - com metáforas para conduzir nossas reflexões.

\footnotetext{
7 Refiro-me aqui à discussão sobre o método da economia política, embora seja um debate que assume um caráter mais abrangente ao longo do escrito. (MARX, 2011.p. 54 e seguintes).
} 


\subsection{No Hall do trabalho teórico}

O interesse deste ensaio foi despertado pelo parágrafo final da introdução de Michael Burawoy ao livro Global Ethnography, já mencionado.

Se é verdade que somos mais cautelosos do que os antropólogos acerca do desaparecimento do estado-nação, isso não significa dizer que nada mudou. De fato, o projeto deste livro é especificar o que há de novo sobre o global, o que distingue o pós-moderno global do imperialismo global mais familiar, do qual ele está emergindo. Como sociólogos, levamos Stuart Hall muito a sério quando ele pergunta o que significaria construir hegemonia, não a nível nacional, que é o velho projeto sociológico, mas a nível global; que é o novo projeto sociológico(grifo meu) ${ }^{8}$ (BuRAwoY, op. cit. p. 35).

Stuart Hall destaca-se, antes de tudo, por sua ação intelectual politizada. A teoria, para o autor, longe de ser apenas uma vontade de verdade, é tida como um conjunto de conhecimentos e uma prática que sempre pensa em intervenções efetivas no mundo (HALL, 2009). Sua trajetória como um intelectual diaspórico, ou seja, como alguém que de fato experimentou o global nas profundezas de sua existência, não é algo pouco significativo, e quando se tem em mente os trabalhos político -intelectuais que o autor realizou na Grã-Bretanha - interior do Estado-nacional -, imediatamente somos convidados a refletir acerca das maneiras como ele próprio pensaria a questão da "hegemonia a nível global" e o papel do trabalho intelectual. Este ensaio se assenta quase que exclusivamente nas reflexões do autor, isso não por uma idolatria acadêmica, mas pelo simples fato de que provavelmente ninguém pensou mais sobre os vínculos entre etnicidade, cultura, poder, mídia, e uma série de outros elementos com fins de transformação social do que Stuart Hall. Não é mera coincidência, nesse sentido, que Burawoy encerre a introdução do livro com as provocações de Hall, que assim como os Estudos Culturais ${ }^{9}$, ainda é pouco conhecido no cenário brasileiro. 0 central aqui não é o que Stuart Hall tem a dizer sobre globalização ou em qual das vertentes apresentadas - global como contexto; global como o que está em todos os lugares; global como unidade diferenciada - o autor se encaixa, mas sim, o convite que sua obra como um todo nos faz para repensarmos politicamente processos "globais". Tentaremos, assim, "trabalhar com" (e não através de) Stuart Hall de maneira antropofágica, do mesmo modo como ele próprio:

deglutiu Marx, Gramsci, Bakhtin. Saboreou Louis Althusser, Raymond Willians, Richard Hoggart, Fredric Jameson, Richard Rorty, Jacques Derri-

\footnotetext{
8 Tradução livre.

9 Em agosto de 2012 foi realizado um levantamento preliminar acerca do número de grupos de pesquisa com a palavra-chave "estudos culturais" no banco de dados do CNPq. A área de Ciências Humanas possuía 107 grupos na temática, desses, apenas 23 pertencentes à Sociologia ou Antropologia, sendo 11 nesta e 12 naquela. Este levantamento foi posteriormente apresentado (BoRDA, 2013.) no IV Seminário Internacional do Programa de Pós-Graduação em Sociologia da UFSCar.
} 
da, Michel Foucault, E. P. Thompson, Gayatri Spivak, Paul Gilroy, com algo de Ien Ang, Cornel West, Homi Bhabha, Michele Wallace, Judith Butler, David Morley, assim como ingeriu Doris Lessing, Barthes, Weber, Durkheim e Hegel (Sovik, 2009. p. 9-10).

\title{
2. Reflexões sobre a Terra no exterior
}

Stuart Hall nasce em Kingston na Jamaica em 1932, três tons mais escuro que o resto de sua família. "Etnicamente, a família era bem mista - composta de africanos, indianos, portugueses e judeus." (HALl et CHEN, 2009. p. 385.) A experiência do hibridismo no interior do núcleo familiar, aliada justamente às contradições decorrentes de tal fato, são fundamentais para se compreender a trajetória de Hall. Quando ele completa dezessete anos sua irmã tem um colapso nervoso, do qual nunca mais se recupera. Ela começa um relacionamento com um estudante de medicina de Barbados, negro, que imediatamente foi negado pelos pais de Stuart Hall. Foi um momento chave:

\begin{abstract}
De repente me conscientizei da contradição da cultura colonial, de como a gente sobrevive à experiência da dependência colonial, de classe e cor e de como isso pode destruir você, subjetivamente. [...] Aprendi, em primeiro lugar, que a cultura era algo profundamente subjetivo e pessoal, e ao mesmo tempo, uma estrutura em que a gente vive. [...] Desde então, nunca mais pude entender por que as pessoas achavam que essas questões estruturais não estavam ligadas ao psíquico - com emoções, identificações e sentimentos, pois para mim, essas estruturas são coisas que a gente vive. [...] Eu não ia ficar lá. Eu não seria destruído por aquilo. Tinha que sair de lá. Senti que nunca mais deveria voltar para lá, pois seria destruído (id. ibid. p. 390-391).
\end{abstract}

É nessa tentativa de fuga dos impactos perversos das estruturas sociais sobre os indivíduos que Hall migra para a Inglaterra, onde permaneceu até sua morte, dia 10 de fevereiro deste ano. Sua experiência é, por excelência, a dos sujeitos hifenizados, plurais e parciais, que costumamos apontar como arquetípicos da pós-modernidade. Desse modo, seu pensamento esteve sempre preocupado com o contexto de um império britânico decadente, ao mesmo tempo em que nunca conseguiu tirar o pé do Caribe; a chegada à Inglaterra em 1951 para estudar em Oxford, e a adoção da Grã -Bretanha como lar nunca o puderam fazer inglês.

De maneira geral, seu nome hoje está associado aos Estudos Culturais, que segundo consta o mito ${ }^{10}$, Hall é um dos pais criadores. Na década de 1960, "não havia

\footnotetext{
10 Utilizo a expressão "segundo consta o mito" pois a formação de toda e qualquer área disciplinar, incluindo, é claro, a formação dos próprios Estudos Culturais, sempre é um processo mais complexo e multifacetado do que geralmente nos é apresentado, e apenas ganha inteligibilidade a partir de uma narrativa que lhe garante uma identidade. Para Hall, essas narrativas da identidade - incluindo também a disciplinar - têm como principal função, assim como os conceitos, "ajudar-nos a dormir bem à noite", uma vez que "nos dizem que há uma espécie de terreno estável que muda de maneira muito lenta." (HALL, 2010b. p. 316. Tradução livre) A narrativa oficial da origem dos Estudos Culturais aponta os trabalhos seminais de Richard Hoggart, Raymond Willians e E P Thompson como formadores desse campo. Hall aparece em tal narrativa como uma espécie de "quarto mosqueteiro" que tem um papel vital para o desenvolvimento do campo na Inglaterra e no resto do mundo, principalmente por
} 
uma disciplina que assumisse com seriedade o estudo das formas e produções culturais contemporâneas, e menos ainda, que tratasse de compreender as estreitas relações entre o cultural e o político." ${ }^{11}$ (RESTREPo et al, 2010. p. 7). Coube a Hall e outros autores, como Raymond Willians, E P Thompson e Richard Hoggart (CEvAsco, 2003; SILvA, 2010), assim, a tarefa de criação de um centro com esses objetivos. Os impactos foram tão grandes no cenário acadêmico anglófono que grande parte da teoria cultural contemporânea seria impensável sem os estudos culturais, e sua expansão mundial abriu as portas para abordagens como pós-colonialismo e a teoria queer (MISKOLCI, 2009).

\subsection{Diálogos locais e disputas conjunturais.}

Quais as contribuições que Stuart Hall pode dar para este ensaio? Em primeiro lugar, sua experiência como imigrante jamaicano o levou a sempre dar especial atenção à forma como a cultura é constitutiva do lugar de onde se pensa. A isso, Hall sugere o conceito de política do lugar (politics of location), não para propor que o pensamento "está necessariamente limitado e ensimesmado pelo lugar de onde provém" (HALl apud Restrepo et al, op. cit. p. 8), mas sim, para destacar que há sempre algum tipo de posicionalidade. Em segundo lugar, hiperhistoricidade de seu pensamento, que bem poderia ser chamado de conjunturalista. A visão de teoria para o autor é a de "um conjunto de conhecimentos contestados, localizados e conjunturais, que têm de ser debatidos de um modo dialógico." (Hall, 2009a. op. cit. p. 203). É por isso que Hall trabalha com uma distinção que perpassa sua obra entre o que ele entende como o trabalho acadêmico e o trabalho intelectual. Para Hall, a única teoria que vale a pena ser guardada é aquela contra a qual nós sempre lutaremos. Por fim, é provável que o terceiro ponto seja a heterodoxia de seu pensamento, "que, por um lado, afirma a importância do simbólico na estruturação da realidade social mas, por outro lado, debate com quem sustenta que, uma vez que a realidade social está constituída discursivamente, então o único existente é o 'discurso'." (RESTREPo et al, op. cit. p. 9). Qualquer semelhança com a terceira via de interpretação do global não é mera coincidência. O pensamento de Stuart Hall é o que bem poderíamos chamar de um pensamento "sem garantias", ou seja, "uma forma de analisar a realidade social fora das estabilizações derivadas pelos determinismos estabelecidos e sem as violências epistêmicas feitas em nome das idealizações morais ou políticas. Nesse sentido, seu método é o do "contextualismo radical", isto é, uma opção que enfatiza a compreensão das conjunturas. Trata-se, de fato, de um pensamento historicizante que mostra a contingência do presente, uma vez que a realidade pôde sempre ter adquirido

sua direção do CCCS (Centre for Contemporary Cultural Studies) de Birmingham durante sua fase mais produtiva - 1968-1979 (PRocter, 2004. p. 36).

11 Tradução livre. 
outra forma e porque destaca que sempre pode ser transformada." (id. ibid. p. 10).

\subsection{A localidade da teoria}

Um outro - e talvez o principal - "oximoro" aparenta despertar; como seria possível equacionar uma visão tão conjunturalista de teoria a contextos globais? Acreditamos que aqui é essencial se ter em mente que os conceitos podem operar em níveis de abstração muito distintos, ou se preferirem, escalas. Queremos dizer que são feitos conscientemente para atuar assim, e não se pode correr o risco de interpretar um conceito que opere em um "alto nível de abstração" a partir de seus efeitos em "níveis mais baixos", assim como o oposto igualmente gera aberrações sociológicas. Afirmar isso não significa invocarmos qualquer espécie de "teoria de médio alcance" - no sentido mertoniano (1970)-, mas sim, realizarmos sempre o esforço de atenção aos níveis em que operam nossos conceitos. Stuart Hall é um autor que, assim como Gramsci, vai na direção de projetar seus conceitos para trabalhar em "níveis mais baixos" de concretude histórica. (HALL, 2009b) Marylin Strathern afirma algo muito parecido quando discute a noção de escala, enquanto a "organização de perspectivas acerca dos objetos do conhecimento e investigação"12. (STRATHERN, 2004. p. xvi) A autora indica duas ordens, domínio e magnitude, que produzem as medidas internas pelas quais o fenômeno da escala pode ser modificado. Além disso, Strathern afirma que o "coloquialismo 'nível"' (id. ibid. p. xvii) - o mesmo usado por Hall - combina essas duas dimensões. Uma boa metáfora para a compreensão do esquema é fornecido pela ideia mapeamento de alguma região, que no caso seria um objeto de investigação. Nesse sentido, é provável que ambos os autores concordassem com a afirmação de que não há diferença, em termos de complexidade, entre estudar fluxos globais de capital (alto nível de abstração, ou simplesmente, um tipo específico de domínio e magnitude) e as relações parentesco em alguma aldeia no interior do Quênia (baixo nível de abstração, ou simplesmente, outro tipo específico de domínio e magnitude). Apenas se deve estar ciente do nível em que operam os conceitos usados, ou qual a escala com a que se trabalha. Em outras palavras; "o que este termo ou este grupo de termos me permite ver? 0 que ele deixa de fora? Com qual dimensão da vida humana estou lidando quando olho as coisas desde esta posição? e etc."

Se é verdade que Stuart Hall dedica sua análises a "níveis mais baixos de concretude histórica" o mesmo não significa dizer dos temas de sua pesquisa. Na realidade, nosso esforço é justamente o de demonstrar - com a ajuda de Hall - a não incompatibilidade entre textos locais e contextos globais. Entre os inúmeros temas

12 Tradução livre. 
que Hall estudou, tais como o tema da globalização ${ }^{13}$ - com especial ênfase nas trocas culturais "populares" -, as diásporas ou até mesmo a estrutura racial da África do Sul, muitos se destacam por precisamente se enquadrarem no que o nosso imaginário social pensa como "global". A forma de aproximação de tais temáticas por parte do autor, entretanto, seguiu o modelo do parágrafo anterior e não raras vezes apelou a recursos linguísticos como metáforas e metonímias para a melhor compreensão dos objetos. 0 ponto é que a construção de discursos contra-hegemônicos a nível global, muito simplificadamente, passa por uma tomada de consciência, em primeiro lugar, do lugar de onde se fala. Em seguida, pela adequação dos conceitos às dimensões estudadas, a vinculação às diferentes matrizes de poder que estruturam tais dimensões, e por fim, a construção de universais que disputarão em uma guerra de posições os corações e mentes da população global. Do que se tratam esses universais que a todo momento retornamos?

\section{Saída}

A essa altura se espera que os objetivos deste ensaio estejam suficientemente claros, apesar de sua linguagem pouco direta. Queremos demonstrar que um exame mais sofisticado do global pode ser propiciado ao se revisitar os escritos de Stuart Hall, que a partir de certas formulações do autor é possível se traçar um refinamento de alguns dos paradigmas interpretativos das ciências humanas. Não queremos dizer que Hall tenha a resposta definitiva a nenhuma das questões colocadas ou colocáveis, insistimos. Somente que o caráter disperso de seus escritos, ao mesmo tempo em que revelam seu desejo de nunca transformar suas reflexões em um sistema teórico fechado, permitem tratá-los levando-se em conta as múltiplas conexões que eles possibilitam, basta o leve giro de um observador neste caleidoscópio intelectual para que todas as peças se recombinem e produzam algo novo, uma ruptura, ou pelo menos uma problematização construtiva dos lugares de onde falamos.

Desse modo, se sempre há algum tipo de posicionalidade em nosso pensamento, seria no mínimo intelectualmente conveniente ver o que os "Outros" teriam a dizer sobre o Mundo que habitamos. Alguns dizem ser isso o que sustenta a dimensão crítica do pós-colonialismo, "um conjunto de práticas e discursos que desconstroem a narrativa colonial tal como foi escrita pelo colonizador, e tenta substitui-la por narrativas escritas do ponto de vista do colonizado" (SANTos apud ALMEIDA, 2013. p. 11). Nessa direção, Hall nos instiga a pensar o trabalho intelectual, assim como a cultura, como um local de lutas e disputas pelo significado, algo cujas implicações não são pequenas. Realizar um trabalho intelectual sério é antes de tudo não tra-

\footnotetext{
${ }^{13}$ E aqui é provável que ele se enquadrasse mais na primeira vertente das abordagens apresentadas.
} 
vesti-lo de neutro através do prisma malicioso da "cientificidade". É levar em conta o engajamento com a realidade da "dor". Assim, tais "narrativas escritas do ponto de vista do colonizado" se tornam uma prerrogativa política, ouvi-las e elevá-las como dignas é possivelmente um dos grandes desafios intelectuais do nosso tempo, tratase da construção de diálogos horizontais. 0 fato é que elas não são novas, sempre estiveram aí apesar das tentativas de silenciá-las. Pode o subalterno ser ouvido? Eis uma questão que, caso respondida afirmativamente, implicaria necessariamente em orações bizarras e quase anedóticas como "a volta dos que não foram". Como esse parece ser o caso, isto é, que a voz do subalterno é encarada como novidade, trabalharemos nesta lacuna para chamar a atenção às contradições inerentes aos projetos globais de luta.

\subsection{A volta dos que não foram}

Durante todo o texto repetimos o termo "universais", sendo agora a hora de precisá-lo. Neste texto encararemos o tema a partir das reflexões de Anna Tsing, citada na primeira parte. A princípio, a ideia de 'universais' pode parecer extremamente problemática, isso pois ao longo do século XX criou-se lentamente uma grande suspeita sobre a ideia de 'universais', que talvez atinja seu ponto máximo com a crítica pós-colonial iniciada com Fanon ${ }^{14}$ e acirrada no fim desse século com autores como Homi Bhabha, Gayatri Spivak, Edward Said e etc. 0 interessante aqui é que Anna Tsing tenta encarar tal problemática de maneira fecunda, em primeiro lugar reconhecendo e levando a sério o fato de que a teoria pós-colonial coloca um desafio aos acadêmicos, o de "posicionar nosso trabalho entre as armadilhas do universal e do culturalmente específico." (TSING, op. cit. p. 1). Isso é resultado do exercício de Tsing de levar às últimas consequências a atenção que a teoria pós-colonial nos fez dar aos jogos de poder que sustentaram a criação de 'universais', e principalmente para os efeitos alienantes que estes tiveram sobre os condenados da terra, ou seja, não aos "quinhentos milhões de homens", mas sim aos "um bilhão e quinhentos milhões de indígenas" que nos fala Sartre (2005, p. 23) no prefácio ao livro ${ }^{15}$ de Fanon. Por outro lado, Tsing nos diz que pouca "atenção foi dada à história do universal, pois ele também foi produzido no encontro colonial." (Tsing, op. cit. p. 1) Tal assertiva não é insignificante, pois direciona nosso olhar para a indissociabilidade entre Modernidade e seu lado escuro, a Colonialidade ${ }^{16}$. Podemos citar como um exemplo

\footnotetext{
14 Destacando-se aqui a impossibilidade de ontologia em uma sociedade colonizada, apontada por ele em Pele negra, máscaras brancas. (2008).

15 Os condenados da Terra.

${ }_{16}$ "A colonialidade do poder é um dos elementos constitutivos e específicos do padrão mundial de poder capitalista. Sustenta-se na imposição de uma classificação racial/étnica da população do mundo como pedra angular do referido padrão de poder e opera em cada um dos planos, meios e dimensões, materiais e subjetivos, da existência
} 
do que fala Tsing o caso da dialética do Senhor e do Escravo de Hegel e a ideia de história universal. Muitos apontam o sistema filosófico de Hegel como um dos mais completos e sofisticados na história do pensamento ocidental (REDYSon, 2011.), um pensamento que se destaca, principalmente, pela construção de universais. Paralelamente, outros autores complementam ao dizer algo curioso, que "A América, tanto do Norte quanto a do Sul, não desempenha virtualmente nenhum papel explícito no pensamento de Hegel" (INwood, 1997. p. 7). Interessam-nos aqui, seguindo a provocação de Tsing, trabalhos como o de Susan Buck-Morss (2011) que, não obstante, revelam uma outra história, negligenciada e apagada, que no caso dialética hegeliana, questionam a visão acima citada de Michael Inwood ao centralizar o papel da Revolução Haitiana para o desenvolvimento do pensamento de Hegel. Tudo isso para ficarmos detidamente em apenas um exemplo do intercruzamento de histórias locais e globais para a construção de 'Uma Modernidade' e os 'universais' que a sustentam. Assim, o livro de Tsing se volta para o outro lado do problema do universalismo, e aqui jaz o segundo ponto de fecundidade de sua crítica.

A especificidade do ponto de vista de Tsing ao encarar os problemas colocados pela crítica pós-colonial a levam a concordar com Gayatri Spivak quando esta afirma o universal como o que nós "não podemos não querer, ainda que frequentemente nos exclua." Segundo Tsing, "o universal nos oferece a chance de participar na corrente global de humanidade." (TsING, op. cit. p. 1). Neste ensaio partilhamos da opinião da autora pois vemos a construção de universais como o caminho para a construção de hegemonia a nível global, o que bem poderíamos chamar aqui de - parafraseando Spivak - um "universalismo estratégico". É necessário, contudo, qualificar que a abordagem por nós aqui adotada não é nova, Walter Mignolo (2000) pensa em seu livro Histórias locais/projetos globais a diferença colonial ${ }^{17}$ como a formação e transformação do Sistema Mundo Moderno/Colonial, e tal conceito de diferença colonial é para o argentino o que captura o lugar, físico ou imaginário, no qual ocorre o conflito entre "dois tipos de histórias locais, dispostas em diferentes espaços e tempos ao redor do planeta."18 (Idem, p. ix) Assim como Tsing, Mignolo reconhece, sem usar os mesmos termos, a centralidade da fricção e os 'universais' - no caso de Mignolo a referência clara é aos projetos globais $^{19}$ - decorrentes de tal atrito para a

social quotidiana e da escala societal. Origina-se e mundializa-se a partir de América" (QuIJANo, 2010. p. 84). Ver também Mignolo (2007), nesta obra o autor demonstra como se gestou a ideia de América Latina, ao mesmo tempo que mostra como o olhar ao futuro tão caro à modernidade só foi possível com a invenção deste continente. Novamente temos aqui a explicitação de como a construção de universais passa diretamente pela fricção com "particulares culturais", ou se preferirem, dinâmicas locais.

17 De acordo com Mignolo, "a diferença colonial é o espaço onde a colonialidade do poder é decretada. É também o espaço onde a restituição do conhecimento subalterno está acontecendo e onde o pensamento fronteiriço está surgindo." (Mignolo, 2000. p. ix).

18 Tradução livre.

19 Global Designs. 
transformação do Mundo. Desse modo, "a diferença colonial é o espaço onde histórias locais inventando e implementando projetos globais encontram histórias locais, o espaço onde projetos globais (no caso de Tsing, provavelmente os universais) devem ser adaptados, adotados, rejeitados, integrados ou ignorados." (Idem). Por fim, trazendo Hall à discussão acrescentamos que tais processos não são garantidos, que os universais produzidos pela fricção entre diferentes histórias locais não implicam necessariamente na construção de projetos emancipatórios, como bem nos mostram os processos históricos do que amplamente chamamos de Modernidade. 0 desafio, assim, passa a ser a intervenção intelectual no interior de tais fricções, padrão este de intervenção que pode ser apreciado de maneira dispersa nos escritos de Stuart Hall. Como evitar que as decorrências de tais processos não se convertam nas alienações psíquicas observadas historicamente na marcha do Sistema Mundo? Ainda, como fazê-lo sem deixar que este pensamento focado no desmascaramento do funcionamento do poder e as lógicas de hegemonias não caia no estabelecimento de qualquer lugar "seguro" de onde se pode falar? São questões abertas cujas respostas transcendem nossas capacidades neste ensaio, mas que ainda assim nos colocam frente ao fato de que a capacidade de viver com a diferença será o assunto chave do século XXI (HALl, 2010a. p. 560).

A construção dos 'universais', assim, para ambos os autores citados nesta seção sempre passa e passou pelo contato com a diferença, mesmo que para sua manutenção. $O$ fracasso do exercício dos 'universais' em situações coloniais, ou ainda no interior dos centros metropolitanos, revela que a própria repetibilidade dos 'universais' não raras vezes extraiu sua potência das impossibilidades práticas de sua realização, naquela mímica (mimicry) do colonizado que nos fala Homi Bhabha (2013) em 0 Local da Cultura - que por sinal "nunca está muito longe de ser uma chacota (mockery), uma vez que parodia o que imita" (Ashcroft et al, 1998, p. 139) ${ }^{20}$. Queremos dizer que a existência da diferença, transformada em desigualdade, foi descoberta/criada na/pela tentativa de exercício desses universais, e, portanto, é da dialética de histórias locais implementando projetos globais com as práticas de seres humanos reais no mundo que os universais retiram sua qualidade distintiva, ao mesmo tempo em que nos atiram a um futuro incerto. ${ }^{21} \mathrm{O}$ fluxo de fricções que ocorre no momento atual necessita uma tradução em termos que possam mais ou menos conduzir seus impactos com fins menos perversos, com uma linguagem menos bipartida que nega o que ela mesma propõe. 0 universalismo estratégico é antes de tudo um universalismo que admitidamente reconhece sua origem particular e o

\footnotetext{
20 Tradução livre.

${ }^{21}$ A ambivalência do discurso colonial e a decorrente criação de zonas de enunciação híbridas, a emergência de pensamentos fronteiriços e etc. As diferentes terminologias neste caso fazem pouca diferença pois todas trazem à tona a contingência de qualquer "assemblage" assentado em universalismos.
} 
local de onde se fala, é por excelência a expressão de que não há paradoxo entre o trabalho intelectual exercido conjunturalmente e projetos globais.

\title{
3.2. Para Stuart Hall: Metáforas de transformação
}

O universalismo estratégico que tangenciamos na seção anterior retira sua força de seu caráter metafórico. Ora, se estamos conscientes dos perigos de transformar pontos de adesão temporária à luta política em sistemas interpretativos ou éticos fechados e fixos, por que correríamos o risco de virar nossa arma contra nós mesmos, tendo em vista que 'não há garantias'? 0 ato de teorizar que defendemos é muito mais a criação de uma Feria preocupada em ser tudo, menos, Teoria, e essa concepção é traduzida na forma como Stuart Hall pensou as metáforas de transformação.

\begin{abstract}
As metáforas de transformação devem fazer pelo menos duas coisas. Elas nos permitem imaginar o que aconteceria se os valores culturais predominantes fossem questionados e transformados, se as velhas hierarquias sociais fossem derrubadas, se os velhos padrões e normas desaparecessem ou fossem consumidos em um "festival de revolução", e os novos significados e valores, novas configurações socioculturais, começassem a surgir. Contudo, tais metáforas devem possuir também valor analítico. (grifo meu) (HALL, 2009c. p. 205).
\end{abstract}

Isso deve ser retido pois não queremos que todas as reflexões deste texto, qualificadas como "metáforas", transformem-se em discursos vazios sem nenhum valor heurístico. A própria teoria como metáfora absorve essa conotação implícita de metáfora que nos fala Hall, algo como uma metametáfora. A questão colocada por Burawoy, que citamos na primeira parte, é muito consistente com a abordagem que realizamos, uma vez que sem apelar ao esvaziamento analítico, "permite-nos imaginar o que aconteceria se os valores culturais predominantes fossem questionados e transformados". Construir hegemonia a nível global é um esforço que exige um posicionamento intelectual muito distinto do que geralmente é cobrado de alunos nos cursos de Ciências Sociais país afora, um posicionamento encontrado em Stuart Hall. Claro que tudo isso tem seus custos, em um artigo recente os autores afirmam que muito das abordagens que em alguma medida se aproximam da de Stuart Hall levam à "diluição da perspectiva científica da sociologia numa visão culturalista e relativista que teria reduzido enormemente a especificidade teórica e metodológica - para alguns outros também a qualidade - da sociologia brasileira", e sarcasticamente completam: "a sociologia brasileira está se tornando uma grande especialista na pesquisa sobre 'a cor do umbigo da cobra gay de Madureira"'(BARBosa et al, 2014, p. 148). A essa nostalgia de tempos em que as posições intelectuais podiam ser facilmente não problematizadas, respondemos com um dos questionamentos do início deste texto: 
quais as possibilidades de prática política a uma "ciência" que se encontra no olho do furacão aporético dos "novos tempos"? Uma coisa é certa: "não há garantias". A proposta deste ensaio, assim, é a de um deslocamento nas discussões global/local para o do universais/universalismo estratégico, revelando a nossa insistência na não incongruência entre as reflexões que fazemos sobre situações empíricas mais limitadas e questões políticas mais amplas. Hall e Tsing, desse modo, tocam-se de maneira inesperada.

\section{Referências Bibliográficas}

AlmeidA, J. (2013). “Perspectivas pós-coloniais em diálogo”. In: Crítica pós-colonial: panorama de leituras contemporâneas. Rio de Janeiro, 7 Letras.

AshCroft, B.; Griffiths, G.; Tiffin, H. (1998). Key concepts in post-colonial studies. London e Nova Iorque, Routledge.

Barbosa, M. L. O.; DWYer, T.; BragA, E. (2013). "Esboço de uma morfologia da sociologia brasileira". In: Revista brasileira de sociologia. v 01, no 02, p. 147-178.

BhABHA, H. (2013). O Local da cultura. Belo Horizonte, Editora UFMG.

BordA, E. W. B. (2013). “Estudos Culturais no Brasil: do que estamos falando?" In: Caderno de Resumos. IV Seminário Internacional do Programa de Pós-Graduação em Sociologia da UFSCar - Olhares e diálogos sociológicos sobre as mudanças no Brasil e na América Latina. São Carlos, UFSCar.

Buck-Morss, S. (2011) “Hegel e o Haiti”. In: Novos estudos. - CEBRAP, n.90, p. 131171.

Burawoy, M. (2000). "Reaching for the global”. In: Global ethnography: forces, connections, and imaginations in a postmodern world. Berkeley, University of California Press.

CAnClini, N. G. (2007). A globalização imaginada. São Paulo, Iluminuras.

Cevasco, M E. (2003). Dez lições sobre estudos culturais. São Paulo, Boitempo editorial. FANON, F. (2008). Pele negra, máscaras brancas. Salvador, EDUFBA.

. (2005). Os Condenados da Terra. Juiz de Fora, Ed. UFJF.

HALL, S. (2009a). "Estudos culturais e seu legado teórico". In: Da diáspora: identidades e mediações culturais. Belo Horizonte, Editora UFMG.

(2009b). "A relevância de Gramsci para o estudo de raça e etnicidade". In:

Da diáspora: identidades e mediações culturais. Belo Horizonte, Editora UFMG. 
. (2009c). "Para Allon White: metáforas de transformação". In: Da diáspora: identidades e mediações culturais. Belo Horizonte, Editora UFMG.

. (2010ª). “Cultura, comunidad, nación”. In: Sin garantias: trayectorias y problemáticas en estudios culturales. Popayán, Envión editores.

. (2010b). "Antiguas y nuevas identidades y etnicidades". Sin garantias: trayectorias y problemáticas en estudios culturales. Popayán, Envión editores.

HALl, S.; Chen K. H. (2009). “A formação de um intelectual diaspórico”. In: Da diáspora: identidades e mediações culturais. Belo Horizonte, Editora UFMG.

Inwood, M. (1997). Dicionário Hegel. Rio de Janeiro, Zahar.

LANDER, E. (2011). “Ciencias sociales: saberes coloniales y eurocéntricos”. In: La colonialidad del saber: eurocentrismo y ciencias sociales: perspectivas latinoamericanas. Buenos Aires, CICCUS.

MARX, K. (2011). Grundrisse: manuscritos econômicos de 1857-1858. São Paulo, Boitempo.

Merton, R. (1970). Sociologia: teoria e estrutura. São Paulo, Editora Mestre Jou.

Mignolo, W. (2000). Local histories/global designs: coloniality, subaltern knowledges, and border thinking. Princeton, Priceton University Press.

. (2007). La idea de América Latina. Barcelona, Gedisa editorial.

Miskolci, R. (2009). “Teoria queer e a Sociologia: o desafio de uma analítica da normalização". In: Sociologias, Porto Alegre, ano 11, no 21, pp. 150-182.

ONG, A.; Collier, S. (2005). Global assemblages, anthropological problems. In: Global assemblages: Global assemblages: technology, politics and ethics as anthropological problems. Oxford, Blackwell publishing.

Procter, J. (2004). Routledge critical thinkers: Stuart Hall. Londres/Nova Iorque, Routledge.

Quijano, A. (2010). “Colonialidade do poder e classificação social”. In: Epistemologias do Sul. São Paulo, Cortez editora.

REDYSon, D. (2011). 10 lições sobre Hegel. Petrópolis, Vozes.

Restrepo, E.; WALSH, C.; VISH, V. (2010) “Práctica crítica y vocación política: pertinencia de Stuart Hall en los estudios culturales latinoamericanos". In: Sin garantias: trayectorias y problemáticas en estúdios culturales. Popayán, Envión editores.

SARTre, J. (2005). P. Prefácio. In: Os Condenados da Terra. Juiz de Fora, Ed. UFJF. 
SiLva, TT da. (2010). O que é, afinal, estudos culturais? Belo Horizonte, Autêntica Editora.

SovıK, L. (2009). “Para ler Stuart Hall”. In: Da diáspora: identidades e mediações culturais. Belo Horizonte, Editora UFMG.

Strathern, M. (2004). Partial connections. Oxford, AltaMira Press.

Tsing, A. (2005). Friction: an ethnography of global connection. Princeton, Princeton University Press.

Recebido em Agosto/2014

Aprovado em Fevereiro/2015 